\title{
Transcatheter Device Closure of Atrial Septal Defects in Small Children: Sound Judgment is Key!
}

\author{
Henri Justino
}

$\mathrm{T}$ he inceptive report of nonoperative closure of atrial septal defects (ASD) by King and Mills ${ }^{1}$, in 1974, ushered an era of tremendous evolution in transcatheter device closure of secundum ASDs. Their pioneering efforts were responsible for much of the knowledge we now possess: they established the balloon sizing technique, described assessment of the septal rim adjacent to the atrioventricular valves using angiography (in order to exclude atrioventricular septal defects), and achieved successful defect closure despite a non-self-centering double umbrella device that required a saphenous vein cutdown and a 23 F delivery system! Since then, there has been improved understanding of the role of atrial septal anatomy in selection of patients for this procedure, including the measurement of septal length and assessment of all rims surrounding the defect. ${ }^{2}$ Furthermore, today's devices have undergone major design enhancements to improve their deliverability and retrievability, and their delivery systems have much lower profiles. Finally, the selection of devices on the market today has greatly expanded. Together, these factors have resulting in device therapy essentially supplanting surgical closure of secundum ASDs in older children, teenagers, and adults.

\section{See page 165}

An exception to the widespread application of the se techniques remains: the case of infants and young children. Because ASDs are generally asymptomatic in early childhood, delaying transcatheter closure until children are larger, and device placement is technically less challenging, is usually acceptable. However, there are certain vulnerable populations that may benefit from early closure of an ASD, such as those exhibiting poor growth, those with symptoms of congestive heart failure, and those with chronic lung disease of prematurity. Abolition of a left to right shunt has been shown to improve lung function in children with bronchopulmonary dysplasia, even allowing ventilator-dependent patients to be successfully extubated..$^{3-5}$

In the current issue of Revista Brasileira de Cardiologia Invasiva, Ribeiro et al. ${ }^{6}$ have reported on transcatheter closure of ASDs in children weighing less than $20 \mathrm{~kg}$. Theirs is a vast experience, totaling 80 patients over a span of 15 years, and utilizing a wide variety of devices. They are to be commended for achieving successful closure in all 80 patients, with an extremely low complication rate. Their methodical approach to assessment of rims, septal length, and de tection of multiple fenestrations, is certainly key to their success. However, it must be noted that they very rightly excluded patients with deficient rims (except the retro-aortic rim), or those having a defect potentially requiring a device deemed too large for the child's heart or those in whom a device would likely interfere with surrounding cardiac structures such as the superior vena cava, pulmonary veins, atrioventricular valves, or coronary sinus. Without knowing the total number of patients that they evaluated for potential ASD device closure, it is difficult to know what the success rate would be among the entire denominator of patients $<20 \mathrm{~kg}$ with secundum ASDs. Nevertheless, the message is clear: with proper patient selection, currently available devices can achieve a high success rate with a very low risk of device embolization, permanent heart block, erosion, or surgical device removal.

Our experience is similar to that of Ribeiro et al. ${ }^{6}$. We recently published our data regarding device closure of ASDs in children $<4$ years old. ${ }^{7}$ Over a 10 year period, we had 61 children present to the cardiac catheterization laboratory at Texas Children's Hospital (Houston, Texas, USA) for possible device closure of an ASD, of which almost $20 \%$ had concomitant chronic lung disease. We analyzed all patients referred for 
device closure regardless of defect size, adequacy of rims, or the presence of multiple defects. Of the entire cohort, $48(79 \%)$ underwent successful closure with a device. Of the 13 patients that were not deemed good candidates for device closure, 5 were excluded based on the anatomical features of the ASD on transesophageal echocardiographic (TEE) imaging alone, 3 were excluded after balloon sizing demonstrated a defect too large to close safely with a device, and 5 were ex cluded after attempted placement of a device that resulted in an unfavorable appearance on TEE with subsequent device removal prior to release. We then sought to understand what factors were responsible for successful vs. unsuccessful device closure in this young population. Although both groups had similar weight and body surface area, comparison of the 48 patients who underwent successful device closure with the 13 with unsuccessful closure revealed some important differences: the absolute ASD diameter was significantly larger among those who did not undergo successful device closure $(16.2 \pm 5.6 \mathrm{~mm})$ vs. those with successful closure $(12.8 \pm 4.1 \mathrm{~mm} ; \mathrm{P}<0.01)$, as was the ASD diameter indexed to body weight and body surface area, and the ratio of the ASD diameter to the total septal length.

So, when considering device closure of an atrial septal defect in a small child, the directive should be, as always: primum non nocere! If the child does not have chronic lung disease, or exhibit symptoms of congestive heart failure or impaired growth, there is little to be gained from a precocious procedure to attempt ASD device closure. But as Ribeiro al. ${ }^{6}$ have elegantly and judiciously shown, in well-selected candidates who meet indications for an early device closure, a high success rate at minimal risk are indeed possible. These authors are to be lauded for their sensible and methodical approach to this challenging patient population. After all, it is imperative for interventional cardiologists to be mindful of the fact that a catheter-based approach to repair of congenital heart disease must not be riskier than the conventional surgical approach! We must continually strive to demonstrate that when good judgment is applied, the percutaneous approach does more than save the patient from a scar: it enhances safety.

\section{CONFLICT OF INTEREST}

Consultant for St Jude Medical.

\section{REFERENCES}

1. King TD, Mills NL. Nonoperative closure of atrial septal defects. Surgery. 1974;75(3):383-8.

2. Mathewson JW, Bichell D, Rothman A, Ing FF. Absent posteroinferior and anterosuperior atrial septal defect rims: factors affecting nonsurgical closure of large secundum defects using the Amplatzer occluder. J Am Soc Echocardiogr. 2004;17(1): 62-9.

3. Lammers A, Hager A, Eicken A, Lange R, Hauser M, Hess J. Need for closure of secundum atrial septal defect in infancy. J Thorac Cardiovasc Surg. 2005;129(6):1353-7.

4. Lee YS, Jeng MJ, Tsao PC, Yang CF, Soong WJ, Hwang B, et al. Pulmonary function changes in children after transcatheter closure of atrial septal defect. Pediatr Pulmonol. 2009;44(10): 1025-32.

5. Zaqout M, De Baets F, Schelstraete P, Suys B, Panzer J, Francois $\mathrm{K}$, et al. Pulmonary function in children after surgical and percutaneous closure of atrial septal defect. Pediatr Cardiol. 2010;31(8):1171-5.

6. Ribeiro MS, Pereira FL, Nascimento WT, Costa RN, Kreuzig DL, Pedra SRFF, et al. Factibilidade, segurança e eficácia do fechamento percutâneo da comunicação interatrial em crianças pequenas. Rev Bras Cardiol Invasiva. 2013;21(2):165-75.

7. Petit CJ, Justino H, Pignatelli RH, Crystal MA, Payne WA, Ing FF. Percutaneous atrial septal defect closure in infants and tod dlers: predictors of success. Pediatr Cardiol. 2013;34(2):220-5. 